\title{
Human umbilical cord mesenchymal stem cells ameliorate skin fibrosis development in a mouse model of bleomycin-induced systemic sclerosis
}

\author{
YUAN YANG $^{1,2^{*}}$, SHUAI ZHU ${ }^{1 *}$, YANHONG LI $^{1}$, QIAN LU $^{3}$, QIUYI ZHANG $^{1}$, \\ LINCHONG SU$^{1}$, QIUPING ZHANG ${ }^{1}$, YI ZHAO ${ }^{1}$, YUBIN LUO $^{1}$ and YILIU $^{1}$ \\ ${ }^{1}$ Department of Rheumatology, West China Hospital, Sichuan University, Chengdu, Sichuan 610041; \\ ${ }^{2}$ Department of Rheumatology and Immunology, The First Affiliated Hospital of Chengdu Medical College, \\ Chengdu, Sichuan 610500; ${ }^{3}$ Department of Biomedical Engineering, College of Engineering \\ and Applied Sciences, Nanjing University, Nanjing, Jiangsu 210023, P.R. China
}

Received February 21, 2020; Accepted September 22, 2020

DOI: $10.3892 / \mathrm{etm} .2020 .9387$

\begin{abstract}
Mesenchymal stem cell (MSC) infusion has become a novel therapeutic strategy for complex autoimmune diseases; however, few detailed studies have been performed to investigate the benefit and mechanism of MSC treatment on systemic sclerosis (SSc). The present study aimed to evaluate the therapeutic effect of human umbilical cord derived-MSCs (UC-MSCs) on bleomycin-induced SSc in mice and explore the potential underlying mechanism. The murine SSc model was established by daily subcutaneous injection of bleomycin for 4 weeks, followed with two UC-MSC infusions every 7 days. Skin fibrosis was assessed by $\mathrm{H} \& \mathrm{E}$ and Masson staining. Flow cytometry was used to determine IL-17A, IFN- $\gamma$, tumor necrosis factor- $\beta$, IL-10 and IL-12 levels in serum samples and $\mathrm{T}$ cell subsets in murine spleen. Additionally, gene expression levels of cytokines and fibrosis markers in skin samples were measured by reverse transcription-quantitative PCR. Immunofluorescence staining was performed to track UC-MSC localization and lymphocyte cell infiltration in vivo. UC-MSC treatment exerted an anti-fibrotic role in bleomycin-induced SSc mice, as confirmed by histological improvement, decreased collagen synthesis, and reduced collagen- $1 \alpha 1$, collagen- $1 \alpha 2$, fibronectin- 1 and $\alpha$-smooth muscle actin gene expression levels. The results indicated that UC-MSC treatment only had a limited systematic effect on
\end{abstract}

Correspondence to: Dr Yi Liu or Dr Yubin Luo, Department of Rheumatology, West China Hospital, Sichuan University, 37 Guoxue Xiang, Chengdu, Sichuan 610041, P.R. China

E-mail: yi06liu@yahoo.com

E-mail: luoyubin2016@163.com

${ }^{*}$ Contributed equally

Key words: bleomycin-induced systemic sclerosis, mesenchymal stem cell, T helper 17 cell, interleukin-17A cytokine production in serum samples and $\mathrm{T}$ cell activation in the spleen. By contrast, T helper (Th)17 cell infiltration and activation in skin were efficiently inhibited after UC-MSC infusion, as evidenced by the decreased IL-17A and retinoic acid-related orphan receptor $\gamma t$ gene expression as well as IL-17A production. UC-MSC administration significantly ameliorated bleomycin-induced skin fibrosis and collagen formation primarily by eliminating local inflammation and Th17 cell activation in the skin; however, the systemic inhibitory effect of UM-MSCs on cytokines was less profound.

\section{Introduction}

Systemic sclerosis (SSc) is a chronic connective tissue disorder characterized by progressive fibrosis of the skin and internal organs $(1,2)$. Worldwide, the prevalence of SSc ranges from 7 per million to 489 per million and its incidence ranges from $0.6 /$ million per year to $122 /$ million per year due to geographical variations (3). In particular, the prevalence was reported to be higher in the United States and Australia compared with that in Japan and Europe (3).

To date, the pathogenesis of SSc has not been completely understood. Autoimmune disorders, vasculopathy and fibrosis are the hallmarks of SSc. T helper (Th) subpopulations, including Th1, Th2, Th9, Th17 and Th22 cells and regulatory T cells (Tregs), and the associated cytokines are involved in the autoimmune disorders of patients with SSc (4). SSc displays a Th1/Th2 cytokine imbalance with a predominant Th2 profile (5). IL-4, IL-5 and IL-13 secreted by Th2 cells are also implicated in SSc development either by directly stimulating collagen synthesis and myofibroblast differentiation, or indirectly by regulating immunity and accumulation of extracellular matrix (ECM) after the induction of TGF- $\beta$ secretion (6). However, IFN- $\gamma$, the main cytokine produced by Th1 cells, can obstruct the above responses, leading to an anti-fibrotic effect (7-9). In addition, the levels of Th17 cells are significantly increased in the peripheral blood, skin lesions and lung tissues of patients with SSc $(10,11)$. Although some studies reported that patients with SSc have fewer Tregs 
and more Th17 cells in comparison with those in healthy individuals (11-13), the role of Tregs in scleroderma remains unclear (14). It has also been shown that IL-9-producing Th9 cells may protect from the development of pulmonary fibrosis in SSc by inducing IL-17 production and Treg activation (15).

In addition to the complex pathogenesis, SSc is one of the most difficult immune disease to cure, with a cumulative 5-year mortality rate of $25 \%$ from diagnosis (16). Glucocorticoids, disease modifying anti-rheumatic drugs and biological agents are not efficient enough for SSc therapy (17). Hematopoietic stem cell transplantation has been reported to effectively block disease progression and reverse skin fibrosis especially for the treatment of a number of patients with early diffuse cutaneous SSc (18). In addition, mesenchymal stem cell (MSC) transplantation provides another promising therapeutic option. In contrast to bone marrow (BM)-derived MSCs, umbilical cord (UC)-MSCs have received increasing attention due to the easiness of harvest, and fewer ethical and safety issues (19). Moreover, UC-MSCs not only have similar properties to BM-derived MSCs, but also exhibit comparatively elevated expression of immunomodulatory molecules, including TGF $\beta 1$, indoleamine 2,3-dioxygenase (IDO), tumor necrosis factor (TNF)-stimulated gene 6 protein (TSG-6) and prostaglandin E2 (20). The mechanisms by which MSC treatment ameliorates autoimmune diseases remain to be fully elucidated. It has been reported that MSCs exert immunoregulatory or tissue-repairing effects by balancing Th1/Th2 or Treg/Th17 ratios, long-term engraftment at the target site or secretion of paracrine factors (21).

It has also been reported that MSCs and endothelial progenitor cells from patients with SSc lose their potential to differentiate into endothelial cells (22). Vascular wall injury due to autoimmunity or other factors, including infectious agents, nitric-oxide-related free radicals or granzymes, causes structural and functional vasculature abnormalities, which could further lead to fibroblast activation and scleroderma progression (23). Transplantation of MSCs isolated from the healthy population showed an effective therapeutic effect for scleroderma in previous clinical case reports $(24,25)$. These therapeutic effects may be due to the potential differentiation of MSCs into endothelial cells and their participation in the formation of new blood vessels in adults (26). Although studies in certain fibrotic animal models confirmed the therapeutic benefit of MSC transplantation on SSc, indicating its immunoregulatory properties (27-29), further detailed studies of the underlying therapeutic mechanism are required.

The present study evaluated the therapeutic potential of UC-MSC infusion and its effect on collagen synthesis and immune dysregulation in a bleomycin-induced SSc model. The potential molecular mechanism of UC-MSC treatment was investigated in detail, providing new information to expand the knowledge of MSC transplantation in SSc therapy.

\section{Materials and methods}

Cell culture. UC-MSCs were purchased from Chengdu Kangjing (Sichuan Kangbaoli) Biological Technology Co., Ltd. (https://www.konjin.com.cn/ganxibaojishu/) (30,31). and cultured in UltraCULTURE Serum-free Cell Culture Medium (cat. no. BEBP12-725F; Lonza Group, Ltd.) supplemented with
10\% fetal bovine serum (FBS; cat. no. SH30071; HyClone; Cytiva), $1 \%$ penicillin-streptomycin (cat. no. SV30010; HyClone; Cytiva) and 1\% L-glutamine (cat. no. SH30034; HyClone; Cytiva). The cells were incubated at $37^{\circ} \mathrm{C}$ with $5 \% \mathrm{CO}_{2}$.

Animal experiments. In total, $30 \mathrm{BALB} / \mathrm{C}$ mice were purchased from Chengdu Dashuo Experimental Animal Co., Ltd. Female

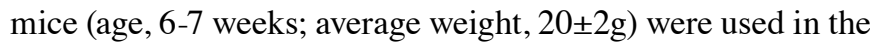
present study. All mice were fed in the specific-pathogen-free (SPF) room in the West China Science and Technology Park of Sichuan University, with room temperature ranging $22-25^{\circ} \mathrm{C}$, humidity ranging 40-60\% and 12-h light/dark cycle. All mice had free access to food and water. Bleomycin (Nippon Kayaku Co., Ltd.) was dissolved in PBS at a concentration of $1 \mathrm{mg} / \mathrm{ml}$. The mice received a daily subcutaneous injection at the dorsal area of either bleomycin or PBS (100 $\mu \mathrm{l}$; administered using a 27-gauge needle) for 4 weeks as described before (32). The PBS injection was used as a control. A total of $1 \times 10^{6}$ UC-MSCs suspended in $100 \mu \mathrm{l}$ PBS were injected into the tail vein of bleomycin-induced SSc mice at day 28 and 35, respectively. Mice were sacrificed at day 42. Blood, skin, and spleen were collected for further experiments. The experimental timeline is presented in Fig. 1A. All studies and procedures were approved by the Committee on Animal Experimentation of the West China Hospital, Sichuan University (approval no. 2017-203).

Staining with Paul Karl Horan (PKH) membrane linkers and in situ PKH67-labeled MSCs tracing. Fluorescent labelling of UC-MSCs was performed by incubating $1 \times 10^{7}$ cells in $1 \mathrm{ml}$ Diluent C containing freshly prepared PKH67 $(10 \mu \mathrm{M}$; PKH67 Green Fluorescent Cell Linker Mini Kit for General Cell Membrane Labeling; cat. no. MINI67; Sigma-Aldrich; Merck $\mathrm{KGaA}$ ) for $10 \mathrm{~min}$ at room temperature. Subsequently, $1 \times 10^{6}$ UC-MSCs were injected into bleomycin-induced SSc mice, as aforementioned. Skin tissues were harvested and fixed in $2 \%$ paraformaldehyde overnight at $4{ }^{\circ} \mathrm{C}$ and embedded in Tissue-Tek O.C.T. compound. Sections (5- $\mu$ m-thick) were air-dried for $1 \mathrm{~h}$ at room temperature before being mounted using 1 drop of mounting medium containing DAPI (cat. no. 0100-20; SouthernBiotech) by following the manufacturer's protocol for frozen sections. The labelled MSCs were observed under an immunofluorescence microscope at x40 magnification.

Flow cytometry analysis. Splenocytes were obtained by crushing the spleen and a gentle filtration through a $40-\mu \mathrm{m}$ cell strainer (BD Biosciences). The red blood cells was removed using red blood cell lysis buffer (cat. no. 00-4333; eBioscience; Thermo Fisher Scientific, Inc.) and incubation for $5 \mathrm{~min}$ at room temperature. Subsequently, splenocytes were washed twice with BioWhittaker ${ }^{\circledR}$ RPMI 1640 media (Lonza Group, Inc.) containing 10\% FBS, $10 \mathrm{mM}$ HEPES, $1 \mathrm{mM}$ sodium pyruvate, $56 \mu \mathrm{M}$ 2-mercaptoethanol, 1\% L-glutamine and $1 \%$ penicillin/streptomycin. Single-cell suspensions were cultured in 96-well flat-bottomed plates in triplicate at a density of $1 \times 10^{6}$ cells $/ \mathrm{ml}(200 \mu \mathrm{l})$ in the aforementioned complete RPMI 1640 medium for $6 \mathrm{~h}$ before detection by staining with antibodies. For intracellular staining of IL-17A, IL-4 and IFN- $\gamma$, cells were 
A
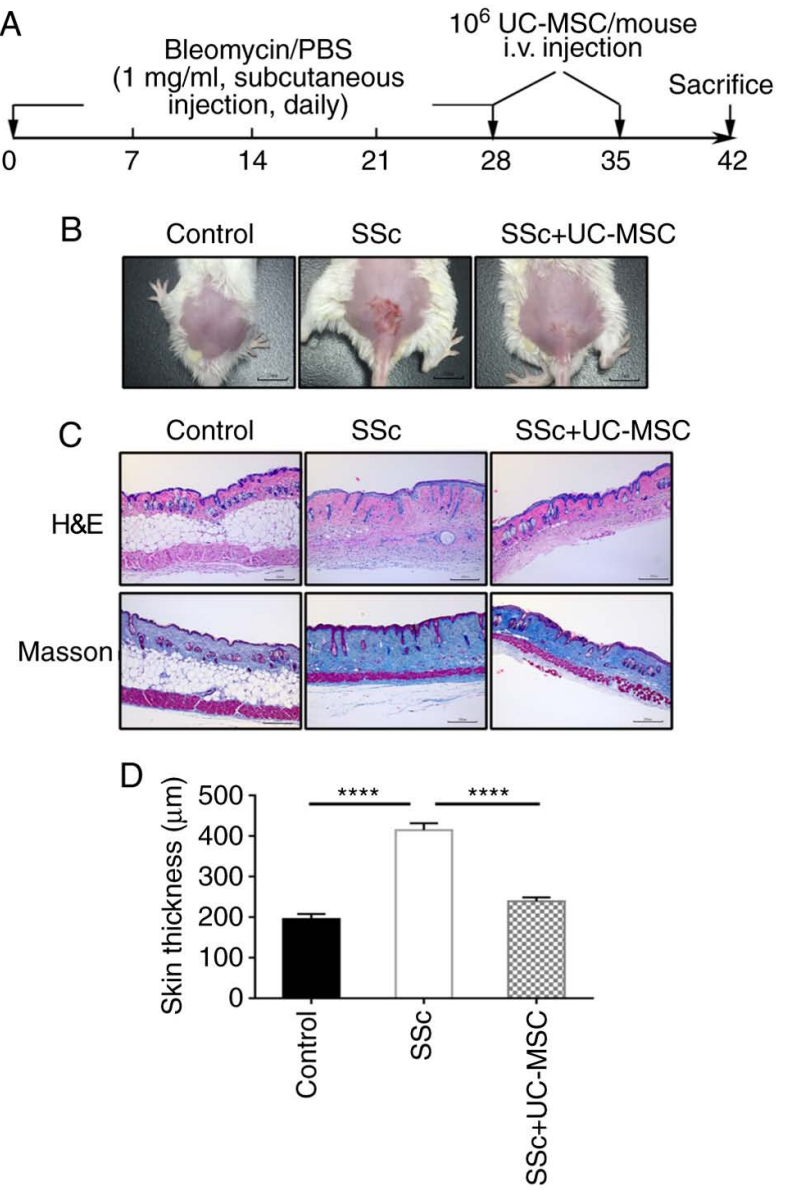

Figure 1. UC-MSC treatment ameliorates bleomycin-induced skin fibrosis (A) The experimental timeline. (B) Visible changes in the mouse dorsal skin (C) Representative images of H\&E and Masson trichrome-stained sections in different groups (magnification, $\mathrm{x} 20$ ). (D) Changes in dermal thickness ( $\mathrm{n}=10 \mathrm{mice} /$ group). Data are presented as the mean \pm SEM. ${ }^{* * * *} \mathrm{P}<0.0001$ UC-MSC, umbilical cord-mesenchymal stem cell; SSc, systemic sclerosis.

stimulated with $50 \mathrm{ng} / \mathrm{ml}$ phorbol 12-myristate 13 -acetate (PMA; Sigma-Aldrich; Merck KGaA), $1 \mu \mathrm{g} / \mathrm{ml}$ ionomycin (Sigma-Aldrich; Merck KGaA) and $5 \mathrm{ug} / \mathrm{ml}$ protein transport inhibitor containing monensin (GolgiStop ${ }^{\mathrm{TM}}$; BD Biosciences) at $37^{\circ} \mathrm{C}$ with $5 \% \mathrm{CO}_{2}$ for $4 \mathrm{~h}$. Monoclonal antibodies for mouse CD4 [1:150 in 2\% BSA (cat. no. A3803; Sigma-Aldrich; Merck KGaA); cat. no. 8545004282; eBioscience; Thermo Fisher Scientific, Inc.], IL-17A (1:40; cat. no. 559502; BD Biosciences), IL-4 (1:100; cat. no. 8517704181; eBioscience; Thermo Fisher Scientific, Inc.) and IFN- $\gamma$ (1:100; cat. no. 8511731181; eBioscience; Thermo Fisher Scientific, Inc.) were used for flow cytometry. Cells were stained with the CD4 antibody in the dark for $30 \mathrm{~min}$ at $4^{\circ} \mathrm{C}$. After incubation with CD4, cells were subsequently fixed in Fixation buffer (eBioscience; Thermo Fisher Scientific, Inc.) at room temperature and protected from light for $30 \mathrm{~min}$. The cells were then added with Permeabilization Diluent (eBioscience; Thermo Fisher Scientific, Inc.) directly followed by centrifugation at $400 \times \mathrm{g}$ for $5 \mathrm{~min}$ at room temperature. For IFN- $\gamma$, IL-4 and IL-17A staining, cells were incubated at $4{ }^{\circ} \mathrm{C}$ and protected from light for $30 \mathrm{~min}$ with antibodies diluted in the Permeabilization Diluent (1:100). Data were collected using a BD FACSCalibur ${ }^{\mathrm{TM}}$ instrument (BD Biosciences) and analyzed using FlowJo software (version 10.6.2; FlowJo LLC).
Cytokine measurement. Serum samples were collected after centrifugation at $1000 \mathrm{x} \mathrm{g}$ and room temperature for $15 \mathrm{~min}$ and stored at $80^{\circ} \mathrm{C}$ until measurement. To measure cytokine levels IL-17A, IFN- $\gamma$, TNF- $\alpha$, IL-10 and IL-12, a Mouse MACSPlex Cytokine Kit (cat. no. 130-101-740; Miltenyi Biotec, Inc.) was used according to the manufacturer's protocols.

Histopathology and immunofluorescence. The impaired skin in the injection area was removed and fixed in $10 \%$ formalin solution for $24 \mathrm{~h}$ at room temperature, dehydrated in a graded ethanol series and embedded in paraffin. Tissue sections (5- $\mu$ m-thick) were then deparaffinized and rehydrated gradually in xylene (twice) followed by a descending ethanol series and distilled water at room temperature. For hematoxylin-eosin (H\&E) staining, the slides were first stained with hematoxylin for $1 \mathrm{~min}$ at room temperature followed by rinsing in tap water, after removing excess background stain in 1\% HCL for $10 \mathrm{sec}$, the slides were then counterstained with eosin for $2 \mathrm{~min}$ at room temperature. The slides were visualized under the light microscope at x10 magnification.

For Masson trichrome staining, a trichrome stain kit (cat. no. ab150686; Abcam) was used by following the manufacturer's protocol. Briefly, the slides were incubated in Weigert's iron hematoxylin (5 min), Biebrich Scarlet-Acid Fuchsin Solution (15 min), Phosphomolybdic-Phosphotungstic Acid Solution (15 min) and Aniline Blue Solution (10 min), all at room temperature. The slides were visualized under the light microscope at $\mathrm{x} 10$ magnification. Skin thickness was calculated in $\mu \mathrm{m}$ digitally using the Olympus stream software (version 1.9; Olympus Coporation) measuring $\geq$ three times from the epidermis to the dermal-fat junction.

For immunofluorescence analysis, after paraffin removal using protocol as aforementioned, epitope retrieval was performed using citrate buffer $\left(\mathrm{pH} \mathrm{6.0)}\right.$ ) at $95^{\circ} \mathrm{C}$ water for 30 min before blocking in $4 \%$ bovine serum albumin (BSA; cat. no. A3803; Sigma-Aldrich; Merck KGaA) in PBS at room temperature for $1 \mathrm{~h}$ and tissue sections were incubated with anti-IL-17A (1:100, cat. no. ab79056; Abcam) and anti-CD3 (1:100, cat. no. ab135372; Abcam) antibodies at $4^{\circ} \mathrm{C}$ overnight. Goat anti-rabbit Alexa Fluor 488 (1:500, cat. no. A11034; Invitrogen; Thermo Fisher Scientific, Inc.) or goat anti-rabbit Alexa Fluor 555 IgG (1:500, cat. no. A21428; Invitrogen; Thermo Fisher Scientific, Inc.) were used as secondary antibodies for incubation at room temperature for $1 \mathrm{~h}$. Nuclei were then stained with one drop of $(\sim 50 \mu \mathrm{l})$ DAPI (cat. no. 0100-20; SouthernBiotech) at room temperature for $2 \mathrm{~min}$. Immunofluorescence images were captured using a Zeiss LSM 510 META confocal microscope at x40 magnification. Negative controls, stained only with secondary antibodies, did not result in marked fluorescence and were omitted from the figures.

Hydroxyproline content assay. Collagen content in skin tissues was measured with a Hydroxyproline Assay kit (Nanjing Jiancheng Bioengineering Institute). The impaired skin tissues in the injection area $(100 \mathrm{mg})$ was placed in a test tube and mixed with $1 \mathrm{ml}$ hydrolysate $(6 \mathrm{~mol} / \mathrm{l} \mathrm{HCl}$, catalog no. 1.10164, Merck Millipore). After the tissues were hydrolyzed in a $95^{\circ} \mathrm{C}$ water bath for $20 \mathrm{~min}, \mathrm{pH}$ value was 
adjusted to 6.0-6.8. A total of $5 \mathrm{mg}$ activated charcoal was added into tissue samples, mixed, and centrifuged at $1368 \mathrm{x} \mathrm{g}$ at room temperature for $10 \mathrm{~min}$. Supernatant $(1 \mathrm{ml})$ was collected into a new tube and incubated with chloramines-T solution for $20 \mathrm{~min}$ at room temperature. The mixture was then heated with para-dimethylaminobenzaldehyde at $60^{\circ} \mathrm{C}$ for $20 \mathrm{~min}$. The absorbance at $550 \mathrm{~nm}$ was read with a 1500 Multiskan Spectrum Microplate Reader (Thermo Fisher Scientific, Inc.). The hydroxyproline content was expressed in $\mu \mathrm{g} / \mathrm{mg}$ of skin.

Reverse transcription-quantitative PCR (RT-qPCR) anal$y$ sis. Total RNA was isolated from the impaired skin tissue in the injection area using TRIzol ${ }^{\circledR}$ reagent according to manufacturer's protocol (Invitrogen; Thermo Fisher Scientific, Inc.). Total RNA was treated with DNase I (cat no. 2270A; Takara Bio, Inc.) at $37^{\circ} \mathrm{C}$ for $20 \mathrm{~min}$ and reverse transcribed into cDNA using PrimeScript ${ }^{\mathrm{TM}} \mathrm{RT}$ reagent Kit (cat. no. RR037A; Takara Bio, Inc.) with oligo d(T) primers at $37^{\circ} \mathrm{C}$ for $15 \mathrm{~min}$ and $85^{\circ} \mathrm{C}$ for 5 seconds. Gene expression was quantified using QuantiNova ${ }^{\circledR} \mathrm{SYBR}^{\circledR}$ Green PCR Kit (cat. no. 208054; Qiagen $\mathrm{GmBH}$ ) using the following thermocycling conditions: Initial denaturation step of $2 \mathrm{~min}$ at $95^{\circ} \mathrm{C}$, followed by 40 times of $95^{\circ} \mathrm{C}$ for $5 \mathrm{sec}$ and $60^{\circ} \mathrm{C}$ for $10 \mathrm{sec}$ on a CFX Connect system (Bio-Rad Laboratories, Inc.). $\beta$-actin was used as the internal reference gene. Quantification was performed using the $2^{-\Delta \Delta \mathrm{Cq}}$ method (33). The sequences of the sense and antisense primers were as follows: $\beta$-actin forward, 5'-CATTGCTGACAGGATGCAGAAGG-3' and reverse, 5'-TGCTGGAAGGTGGACAGTGAGG-3'; IL-17A forward, 5'-CAGACTACCTCAACCGTTCCAC-3' and reverse, 5'-TC CAGCTTTCCCTCCGCATTGA-3'; TGF- $\beta 1$ forward, 5'-TG ATACGCCTGAGTGGCTGTCT-3' and reverse, 5'-CAC AAGAGCAGTGAGCGCTGAA-3'; IL-6 forward, 5'-TAC CACTTCACAAGTCGGAGGC-3' and reverse, 5'-CTG CAAGTGCATCATCGTTGTTC-3'; retinoic acid-related orphan receptor $\gamma \mathrm{t}(\mathrm{ROR}-\gamma \mathrm{T})$ forward, 5'-GTG GAGTTT GCCAAGCGGCTTT-3' and reverse, 5'-CCTGCA CATTCT GACTAGGACG-3; collagen-1 $\alpha 1$ (Col-1 $\alpha 1$ ) forward, 5'-CC TCAGGGTATTGCTGGACAAC-3' and reverse, 5'-CAG AAGGACCTTGTTTGCCAGG-3'; collagen-1 $\alpha 2$ (Col-1 $\alpha 2)$ forward, 5'-TTCTGTGGGTCCTGCTGGGAAA-3' and reverse, 5'-TTGTCACCTCGGATGCCTTGAG-3'; $\alpha$ smooth muscle actin ( $\alpha$-SMA) forward, 5'-TGCTGACAGAGGCAC CACTGAA-3' and reverse, 5'-CAGTTGTACGTCCAGAGG CATAG-3'; Fn-1 forward, 5'-CCCTATCTCTGATACCGT TGTCC-3' and reverse, 5'-TGCCGCAACTACTGTGATTC GG-3'; IFN- $\gamma$ forward, 5'-CAGCAACAGCAAGGCGAA AAAGG-3' and reverse, 5'-TTTCCGCTTCCTGAGGCT GGAT-3'; IL-4 forward,5'-ATCATCGGCATTTTGAACGAG GTC-3' and reverse, 5'-ACCTTGGAAGCCCTACAGAC GA-3'.

Statistical analysis. All experimental procedures were performed in triplicate. All analyses were performed using GraphPad Prism software (version 8.0; GraphPad Software, Inc.) Data are presented as the mean \pm SEM. Comparisons were performed using one-way ANOVA followed by Turkey's post hoc test. $\mathrm{P}<0.05$ was considered to indicate a statistically significant difference.

\section{Results}

UC-MSC treatment ameliorates bleomycin-induced skin fibrosis. Compared with the control group, bleomycin administration led to visible skin redness and ulcers (Fig. 1B). However, a marked improvement in the skin lesions was observed after UC-MSC infusion (Fig. 1B). Furthermore, skin thickness was also significantly increased in bleomycin-induced mice compared with the control group (Fig. 1D). Reductions of skin thickness in the SSc group treated with UC-MSCs and in the control group were observed compared with those in the SSc mice (Control vs. SSc group, $\mathrm{P}<0.005$; SSc vs. MSCs treated, $\mathrm{P}<0.005$ ), which was also associated with a marked decrease in collagen deposition in skin, as demonstrated by Masson trichrome staining (Fig. 1C). Taken together, these data indicated that UC-MSC treatment induced an anti-fibrotic effect on a bleomycin-induced model of SSc.

UC-MSC treatment reduces bleomycin-induced collagen synthesis in skin. The effect of UC-MSC infusion on collagen synthesis was subsequently evaluated. Col-1 11 , Col-1 $1 \alpha 2$, fibronectin-1 and $\alpha$-SMA are important genes associated with collagen synthesis (34-37). Bleomycin caused a significantly higher expression of Col-1 $\alpha 2(\mathrm{P}<0.050)$ and a marked increase in Col-1 $\alpha 1$ expression $(\mathrm{P}>0.050)$ at a transcriptional level in skin compared with that in the control group (Fig. 2A). $\alpha$-SMA $(\mathrm{P}<0.050)$ and fibronectin-1 $(\mathrm{P}<0.005)$ gene expression levels also increased by 2.5 -fold and 3.5 -fold in skin of bleomycin-treated mice compared with the control group, respectively. Notably, UC-MSC treatment inhibited bleomycin-induced Col-1 $\alpha 1(\mathrm{P}<0.050)$, Col-1 $\alpha 2(\mathrm{P}<0.050)$, $\alpha$-SMA $(\mathrm{P}<0.050)$ and fibronectin-1 $(\mathrm{P}<0.050)$ gene expression levels, which were comparable to the expression levels in the control group. In addition, there was a statistically significant difference in hydroxyproline content between control and bleomycin-challenged mice $(\mathrm{P}<0.005)$. UC-MSC injection led to a significant decrease in hydroxyproline content after bleomycin treatment $(\mathrm{P}<0.050)$. These data suggested that UC-MSC infusion could effectively ameliorate bleomycin-induced skin fibrosis by regulating collagen synthesis at transcriptional and protein levels.

UC-MSC treatment reduces local inflammation instead of systemically affecting cytokine production in serum. To understand the potential systematic effect of UC-MSC treatment-induced fibrosis remission in bleomycin-induced SSc, the levels of inflammatory cytokines were assessed in serum samples. IL-17A ( $\mathrm{P}>0.999)$ and IFN- $\gamma(\mathrm{P}>0.999)$ levels in sera were not significantly increased in SSc group mice compared with the control, whilst TNF- $\alpha$ production was enhanced by 6-fold compared with the control group $(\mathrm{P}<0.050)$ (Fig. 3A). UC-MSC-treatment significantly reduced TNF- $\alpha(\mathrm{P}<0.050)$ production but had no significant effect on IL-17A levels ( $P>0.050)$. A slight but not significant decrease in IFN- $\gamma$ and IL-12 levels was detected in UC-MSC-treated mice compared with the SSc group. By contrast, the level of anti-inflammatory cytokine IL-10 was enhanced in the UC-MSC-treated group compared with that in SSc mice, although no statistically significant difference was observed. These data indicate that the systemic reduction in cytokine levels only partially 

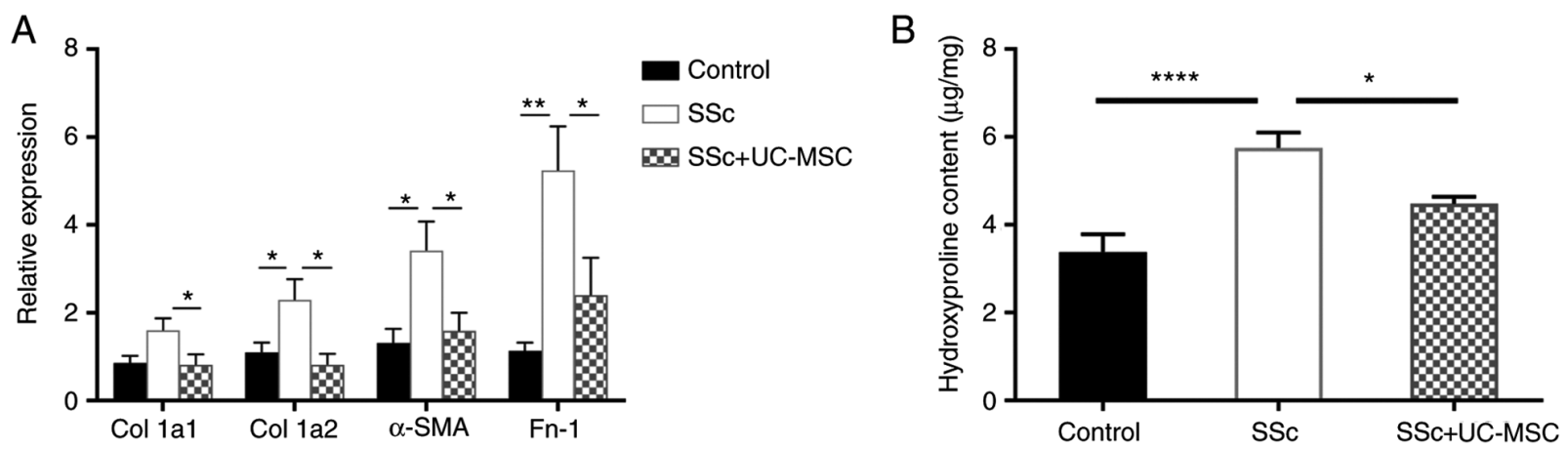

Figure 2. UC-MSC treatment reduces bleomycin-induced collagen synthesis in skin. (A) Effects of UC-MSC administration on Col-1 $\alpha 1$, Col-1 $\alpha 2$, Fn-1 and $\alpha$-SMA gene expression in skin $(\mathrm{n}=8)$. (B) Hydroxyproline content in skin of mice ( $\mathrm{n}=8$ mice). Data presented as the mean $\pm \mathrm{SEM}$. ${ }^{*} \mathrm{P}<0.05,{ }^{* * *} \mathrm{P}<0.01$ and ${ }_{* * * * *} \mathrm{P}<0.0001$. Col-1 $\alpha 1$; collagen-1 $\alpha 1$; Col-1 $\alpha 2$; collagen-1 $\alpha 2$; $\alpha$-SMA, $\alpha$ smooth muscle actin; Fn-1, fibronectin-1; UC-MSC, umbilical cord-mesenchymal stem cell; SSc, systemic sclerosis.
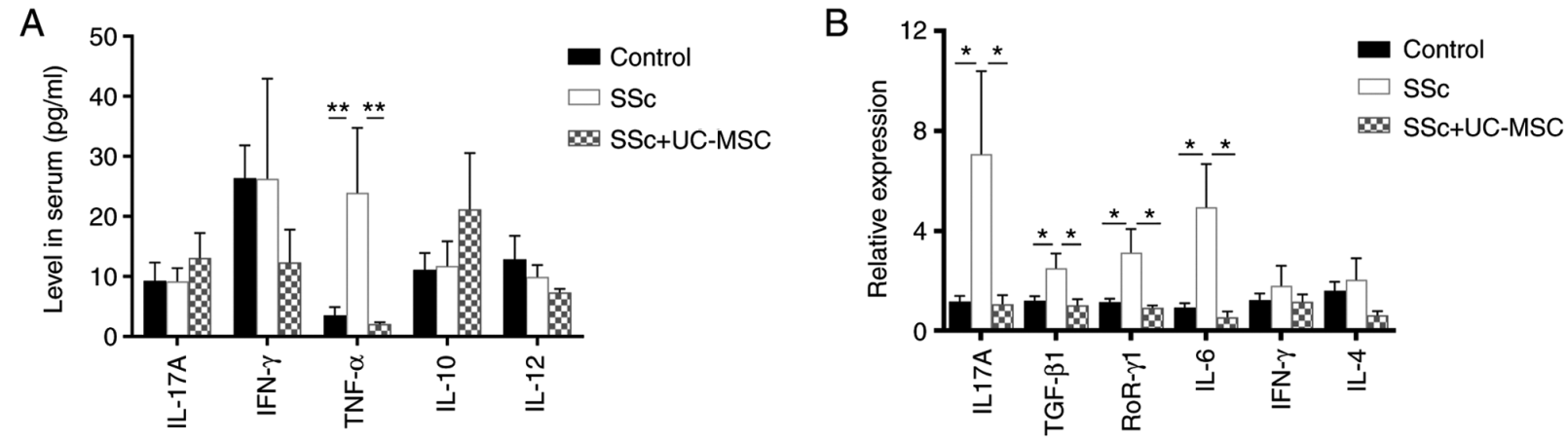

Figure 3. Effect of UC-MSC treatment on cytokine levels in serum and skin samples. (A) The levels of IL-17A, IFN- $\gamma$, TNF- $\alpha$, IL-10 and IL-12 in serum ( $\mathrm{n}=10$ mice). (B) Reverse transcription-quantitative PCR analysis for IL-17A, TGF- $\beta 1$, ROR- $\gamma \mathrm{T}$, IL-6, IFN- $\gamma$ and IL-4 and gene expression in skin ( $\mathrm{n}=10$ mice). Data presented as the mean \pm SEM. ${ }^{*} \mathrm{P}<0.05$ and ${ }^{* *} \mathrm{P}<0.01$. UC-MSC, umbilical cord-mesenchymal stem cell; SSc, systemic sclerosis; ROR- $\gamma \mathrm{T}$, retinoic acid-related orphan receptor $\gamma$ t.

contributed to the therapeutic benefit of UC-MSC treatment on bleomycin-induced SSc in mice. Subsequently, it was determined whether gene expression levels of cytokines implicated in skin fibrosis formation were affected in the impaired skin. As shown in Fig. 3B, IL-17A $(\mathrm{P}<0.050)$, TGF- $\beta 1(\mathrm{P}<0.050)$, ROR- $\gamma \mathrm{T}(\mathrm{P}<0.050)$ and IL-6 $(\mathrm{P}<0.050)$ gene expression levels were significantly enhanced after bleomycin treatment compared with the control group. Furthermore, UC-MSC administration caused a significant reduction in the expression levels of these genes in skin samples from SSc mice (IL-17A, $\mathrm{P}<0.050$; TGF- $\beta 1, \mathrm{P}<0.050$; ROR- $\gamma \mathrm{T}, \mathrm{P}<0.050$; IL-6, $\mathrm{P}<0.050)$. Taken together, these data suggested that UC-MSCs exerted their anti-fibrotic effects on bleomycin-induced SSc primarily by decreasing the level of local inflammation in skin lesions. Systemic levels of inflammatory cytokines in serum were affected to a lesser extent.

UC-MSC treatment exerts anti-fibrotic effects by affecting Th17 cell activation in skin. Considering the implication of $\mathrm{T}$ cell activation in SSc progression (38), the current study examined T cell subsets in spleen using flow cytometry. MSC infusion did not restore $\mathrm{T}$ cell activation in the spleen, where a significant decrease in the overall $\mathrm{CD} 4^{+} \mathrm{T}$ cell percentage was observed in splenocytes from bleomycin-treated mice compared with the control group (Control vs. SSc group,
$\mathrm{P}<0.005$; control vs. MSCs treated, $\mathrm{P}<0.005$; Fig. S1A). Furthermore, there was no significant difference between SSc groups treated and untreated with UC-MSCs (Fig. S1A). No significant difference was also found in the proportion of Th1 and Th2 cell populations among the three groups (Figs. S1B and S2). The percentage of Th17 cells was significantly lower in SSc group splenocytes compared with the control $(\mathrm{P}<0.005)$ and UC-MSC treatment groups $(\mathrm{P}<0.010$; Figs. S1B and S2).

Excluding the impact of UC-MSC treatment on T cell activation in spleen, we next tested whether dysregulation of $\mathrm{T}$ cell immune existed in the impaired skin after bleomycin challenge. $\mathrm{T}$ cells were visualized by immunofluorescence staining. As shown in Fig. 4A, CD3 ${ }^{+}$staining was increased in skin from SSc mice, indicating that bleomycin was able to induce $\mathrm{T}$ cell infiltration in skin. However, the abundance of $\mathrm{CD}^{+} \mathrm{T}$ cells was markedly decreased after UC-MSC treatment. Gene expression levels of IL-17A, ROR- $\gamma \mathrm{T}, \mathrm{IFN}-\gamma$, IL-4 in skin were next measured by RT-qPCR. As shown in Fig. 3B, bleomycin did not affect the level of IFN- $\gamma$ and IL-4 gene expression compared with the control, but there was also no significant difference observed between SSc and UC-MSC-treated mice, suggesting that Th1 and Th2 cell activation was not involved in bleomycin-induced skin fibrosis in mice. However, gene expression levels of IL-17A 

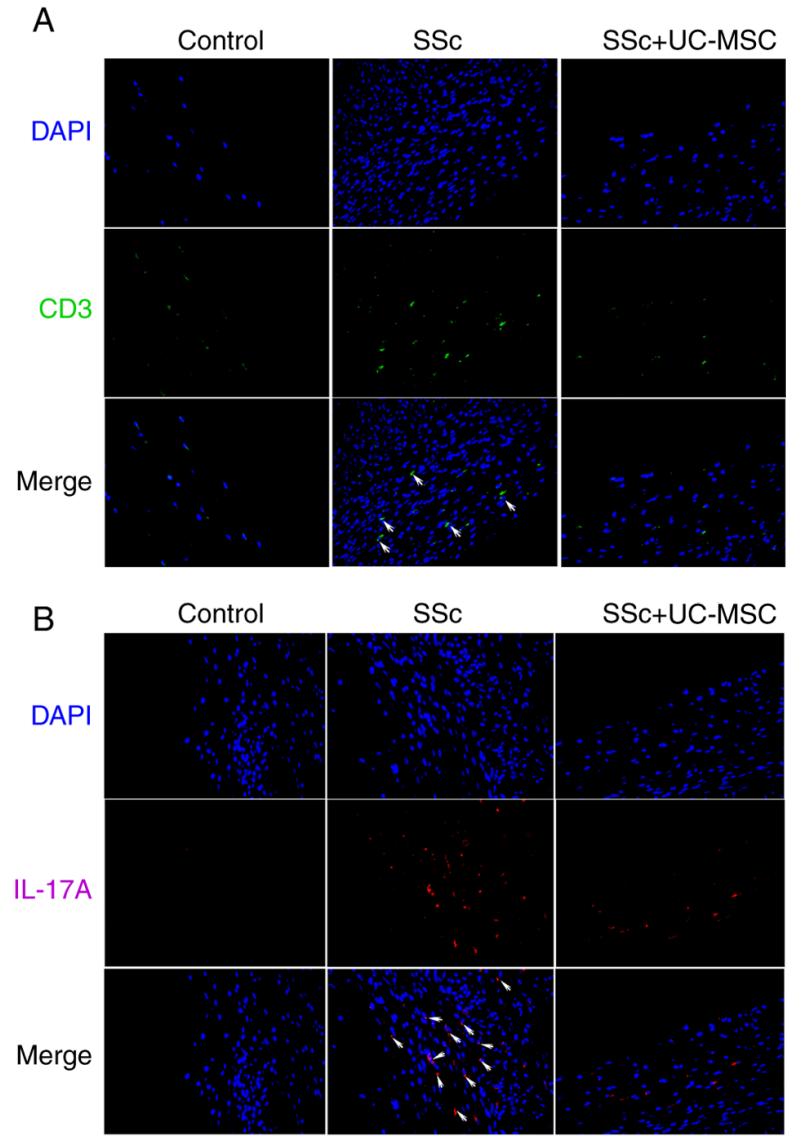

Figure 4. UC-MSC treatment inhibits Th17 cell activation in skin (A) Immunofluorescent staining for CD3 in skin (blue, DAPI; green, CD3; magnification, $x 40$ ). (B) IL-17A staining in skin (red, IL-17A; magnification, x40). UC-MSC, umbilical cord-mesenchymal stem cell; SSc, systemic sclerosis.

$(\mathrm{P}<0.050)$ and ROR- $\gamma \mathrm{T}(\mathrm{P}<0.050)$ were significantly enhanced after bleomycin treatment compared with the control group. Furthermore, UC-MSC treatment significantly reduced the RNA expression of IL-17A $(\mathrm{P}<0.050)$ and ROR- $\gamma \mathrm{T}(\mathrm{P}<0.050)$ in skin (Fig. 3B), indicating that Th17 cell activation might be blocked by UC-MSC treatment. This hypothesis was further confirmed by reduced IL-17A levels in skin from mice receiving UC-MSC infusion compared with the SSc group, as demonstrated by immunofluorescence staining (Fig. 4B). These data demonstrated that UC-MSC treatment displayed an anti-fibrotic effect by regulating Th17 cell activation in the impaired skin.

UC-MSCs survive in the impaired skin. Since Th17 cell activation was observed in the impaired skin in the present study, subsequent experiments were designed to test whether UC-MSCs could regulate Th17 cell activation. To do so, UC-MSCs were labeled with PKH67 before intravenous injection. PKH67-labeled UC-MSCs were observed in the skin lesion from mice receiving UC-MSC infusion (Fig. 5), indicating that transplanted UC-MSs had survived in the skin and prevented Th17 cell activation. Taken together, these data indicated that UC-MSC treatment alleviated disease severity of bleomycin-induced SSc in mice by regulating Th17 cell activation in the impaired skin.

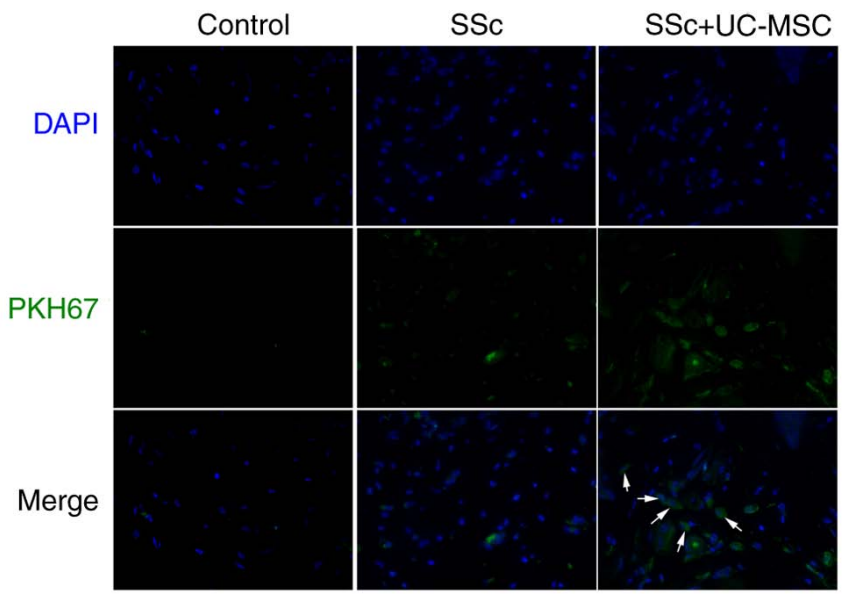

Figure 5. UC-MSCs in localized lesions of the skin. Immunofluorescence staining with DAPI (blue) and PKH67 (green) in skin. White arrows indicate representative MSCs staining. Magnification, x40. UC-MSC, umbilical cord-mesenchymal stem cell; SSc, systemic sclerosis.

\section{Discussion}

MSCs have been reported to exert potent immunosuppressive effects by inhibiting immune cell proliferation and function, and promoting regulatory cell generation, eventually affecting the innate and adaptive immune responses (39). Currently, there is a rising interest in MSC infusion or transplantation therapy for autoimmune diseases, primarily focusing on systemic lupus erythematosus, rheumatoid arthritis and multiple sclerosis using various rodent models (40). In 1999, Yamamoto et al (32) initially reported the subcutaneous injection of bleomycin to the back of BALB/c mice, which successfully induced skin sclerosis and led to histopathological changes similar to SSc. Scholars continuously optimized methods including mouse species, bleomycin dose and the injection cycle (41-43). Bleomycin-induced skin fibrosis model is now accepted as a safe and classical murine model of human skin and lung fibrosis in SSc $(41,42)$. The present study demonstrated that obvious skin and lung fibrosis occurred after continuous bleomycin administration, which is consistent with other publications $(32,43)$.

MSCs are isolated from bone marrow, human umbilical cord and adipose tissue. However, UC-MSCs are considered to be superior in terms of collection procedure, proliferation ability and immunogenicity (44). A previous study has shown comparable efficiency between allo-/xenogeneic BM-MSCs and syngeneic transplantation in reducing fibrotic lesions in mice (29). It has been reported that BM-derived MSCs induce cellular and humoral responses in vivo (45), and MHC mismatch could reduce the efficacy of transplantation (46). In fact, numerous previous publications have reported efficiency and safety of xenogeneic transplantation of human MSCs in several mouse models (47-51). Based on these previous findings, the present study aimed to investigate the efficacy and antigen compatibility of UC-MSCs in bleomycin-induced SSc murine model. UC-MSC treatment efficiently improved the skin thickness and reduced the collagen and extracellular matrix accumulation. During the experiments, all UC-MSC-treated mice survived and none of 
them had systemic/local adverse events, indicating the safety of heterologous MSC infusion, which might be due to the low immunogenicity of UC-MSCs.

The present study aimed to determine whether UC-MSCs exerted the therapeutic effect via systemic or local mechanisms in the bleomycin-induced SSc murine model. Among the cytokines measured in sera, only the TNF- $\alpha$ level was enhanced by bleomycin administration and significantly decreased after UC-MSC treatment. Previous studies have shown that fibroblast hyperplasia is the key component of fibrosis formation $(52,53)$. Cytokines such as TGF- $\beta 1$, IL-6 can promote collagen synthesis of fibroblasts (1). TGF- $\beta 1$ as a paracrine or autocrine cytokine modulates target cells to produce collagen (54). The anti-TGF- $\beta 1$ antibody was previously shown to cause a significant remission of skin sclerosis in the SSc mouse model (55). In normal fibroblasts, IL- 4 can stimulate the production of chemotaxis, TGF- $\beta$, connective tissue growth factor (CTGF) and collagen, promoting hyperplasia and fibrosis (56). IL-4 and its mRNA expression levels were also significantly increased in sclerotic skin and cultured fibroblasts isolated from patients with SSc $(57,58)$. IFN- $\gamma$, a major cytokine secreted by Th1 cells, plays a negative regulatory role in fibroblast activation by inhibiting the expression of collagen gene family and eliminating TGF- $\beta$-induced responses $(59,60)$. In the present study, there was no change in IL-4 and IFN- $\gamma$ gene expression levels in skin between the three study groups. This could be due to time-dependent changes of cytokines in the skin tissues and differences between the patterns occurring in human and animal studies. It has been reported that IL-4 levels are elevated in the early phase of clinical SSc (57). Meanwhile, in a study using mouse models, Okamoto et al (61) found that IL-17, rather than IL-4 or IFN- $\gamma$, contributed to bleomycin-induced skin fibrosis. In the current study, increased gene expression levels of IL-17A, TGF- $\beta 1$ and IL-6, were detected in the skin of bleomycin-treated mice compared with those in the PBS-controlled group, in addition to a significant decrease after MSCs treatment. These findings demonstrated that increased levels of cytokines in the local lesions, reduced after UC-MSC infusion, played a more important role in bleomycin-induced SSc compared with the role of the circulating cytokines.

$\mathrm{T}$ cell activation is known to promote SSc progression (38). In the present study, a reduced percentage of $\mathrm{CD}^{+} \mathrm{T}$ cells among splenocytes was observed in SSc mice. This observation was consistent with Hideaki Ishikawa's study in a bleomycin-induced murine model, which found that the number of $\mathrm{CD}^{+} \mathrm{T}$ cells was significantly decreased in both the thymus and spleen (42). The decrease in $\mathrm{CD} 4^{+} \mathrm{T}$ cells was possibly due to the cytotoxic effect of bleomycin. $\mathrm{CD}^{+} \mathrm{T}$ cells are particularly susceptible to the effects of bleomycin, which may be associated with the induction of autoimmunity in the bleomycin-induced model (42). The percentages of Th1 and Th2 cells in spleen were not significantly different among the three groups. It remains unclear whether Th2 cell-based immune responses play an important role in fibrosis (62-64). The controversial results regarding Th1 and Th 2 cells reported in previous studies, as well as the insignificances observed in the present study, may be due to the differences in animal models, the tissue source of $\mathrm{T}$ cell subset and detection methods. In recent years, important functions of Th17 cells, predominantly secreting IL-17A, IL-17F and IL-22, were found to play a role in the pathogenesis of numerous autoimmune inflammatory diseases, including rheumatoid arthritis, systemic lupus erythematosus and Sjogren's syndrome (65). TGF- $\beta$, IL- 6 and ROR- $\gamma$ t have been reported to be involved in Th17 cell development (66). Furthermore, Th17 cells are associated with the onset of SSc and their numbers are significantly increased in peripheral blood, damaged skin and lung tissue of patients with SSc $(10,11,67)$. IL-17A levels are also higher in the early and active phases of SSc $(68,69)$. In addition, previous experimental studies have examined the significance of Th17 cell abnormalities in the pathological changes of SSc. IL-17A was shown to be involved in lung and skin fibrosis in a bleomycin-induced animal model of SSc (61). IL-17A can promote the secretion of TGF- $\beta$, CTGF and collagen synthesis in SSc fibroblasts (70). In addition, the lack of IL-17A can reduce the skin thickness of TSK-1 mice (61).

In addition to detecting increased total $\mathrm{CD}^{+} \mathrm{T}$ cell levels in local lesions, the present study also identified Th17 cell differentiation and activation, confirmed by the increased IL-17 and ROR- $\gamma$ t gene expression and IL-17A production. Furthermore, PKH67-labeled MSCs were observed in the deep layer of dermis. Previous studies revealed that MSCs can exert an immunoregulatory role via homing and paracrine or direct cell-to-cell contact inhibition to regulate the abundance of T cell subsets, especially Th17 cells $(71,72)$. Therefore, it may be hypothesized that the treatment effect of UC-MSCs on SSc may be achieved by modulating the activation of Th17 cells in the local skin lesions.

The present study had certain limitations. Firstly, autologous MSCs were not used. Isolation and in vitro culture of mouse MSCs is more challenging compared with that of human MSCs due to low yields of cell harvesting, hematopoietic cell contamination, and the lack of specific mouse MSC markers (73). Secondly, due to a limited budget and laboratory conditions, the mechanisms observed in the current study could not be verified further. Regarding the suppressive effect on T cells by MSCs, it has been reported that the mechanisms could be attributed to cell-cell contact, secretion of soluble factors and regulatory T-cell generation (74). Moreover, MSCs could also reduce B cell activation and proliferation (75) and actively interact with macrophages, exerting both anti- and pro-inflammatory effects $(76,77)$. In addition to the immune modulation indicted in the current study, it has previously been reported that the antifibrotic mechanisms of MSCs could be associated with the inhibition of oxidative stress and matrix remodeling, and the inhibition of TGF- $\beta$ in the present study could further mediate adipocyte-myofibroblasts transition (78). These mechanisms could be investigated further in the future.

Taken together, the present study showed that human UC-MSC infusion was able to significantly alleviate skin fibrosis and collagen synthesis in a bleomycin-induced SSc mouse model. UC-MSC treatment exerted an anti-fibrotic role by alleviating local inflammation and Th17 cell activation in the impaired skin, while the systemic inhibitory effect on cytokines played a less important role. 


\section{Acknowledgements}

The authors would like to thank Professor Tony Marion from the University of Tennessee Health Science Center (Memphis, USA) for his technical support and consultation.

\section{Funding}

This study was supported by the National Key R\&D Program of China (grant no. 2016YFC0906201)

\section{Availability of data and materials}

The datasets used and/or analyzed during the current study are available from the corresponding author on reasonable request.

\section{Authors' contributions}

YiL and YLu were responsible for the acquisition of funding. YLu, SZ and YY contributed to conceptualization and performed the experiments. YLu, SZ, YY, YaL, QL, LS, QYZ and QPZ were responsible for the development of methodology. YLu, SZ and YY were responsible for the acquisition of data. YiL, YZ, YLu, SZ and YY were responsible for the analysis and interpretation of data. All authors read and approved the final manuscript.

\section{Ethics approval and consent to participate}

All studies and procedures were approved by the Committee on Animal Experimentation of the West China Hospital, Sichuan University (approval no. 2017-203).

\section{Patient consent for publication}

Not applicable.

\section{Competing interests}

The authors declare that they have no competing interests.

\section{References}

1. Varga $\mathbf{J}$ and Abraham D: Systemic sclerosis: A prototypic multisystem fibrotic disorder. J Clin Invest 117: 557-567, 2007.

2. Chizzolini C, Brembilla NC, Montanari E and Truchetet ME: Fibrosis and immune dysregulation in systemic sclerosis. Autoimmun Rev 10: 276-281, 2011.

3. Chifflot H, Fautrel B, Sordet C, Chatelus E and Sibilia J: Incidence and prevalence of systemic sclerosis: A systematic literature review. Semin Arthritis Rheum 37: 223-235, 2008.

4. Liu M, Wu W, Sun X, Yang J, Xu J, Fu W and Li M: New insights into CD4(+) T cell abnormalities in systemic sclerosis. Cytokine Growth Factor Rev 28: 31-36, 2016.

5. Fujii H, Hasegawa M, Takehara K, Mukaida N and Sato S: Abnormal expression of intracellular cytokines and chemokine receptors in peripheral blood $\mathrm{T}$ lymphocytes from patients with systemic sclerosis. Clin Exp Immunol 130: 548-556, 2002.

6. Wynn TA: Cellular and molecular mechanisms of fibrosis. J Pathol 214: 199-210, 2008.

7. Ghosh AK, Yuan W, Mori Y, Chen Sj and Varga J: Antagonistic regulation of type I collagen gene expression by interferon-gamma and transforming growth factor-beta. Integration at the level of $\mathrm{p} 300 / \mathrm{CBP}$ transcriptional coactivators. J Biol Chem 276: 11041-11048, 2001.
8. UlloaL, Doody J and Massagué J: Inhibition of transforming growth factor-beta/SMAD signalling by the interferon-gamma/STAT pathway. Nature 397: 710-713, 1999.

9. Higashi K, Inagaki Y, Fujimori K, Nakao A, Kaneko H and Nakatsuka I: Interferon-gamma interferes with transforming growth factor-beta signaling through direct interaction of YB-1 with Smad3. J Biol Chem 278: 43470-43479, 2003.

10. Radstake TR, van Bon L, Broen J, Hussiani A, Hesselstrand R, Wuttge DM, Deng Y, Simms R, Lubberts E and Lafyatis R: The pronounced Th17 profile in systemic sclerosis $(\mathrm{SSc})$ together with intracellular expression of TGFbeta and IFNgamma distinguishes SSc phenotypes. PLoS One 4: e5903, 2009.

11. Rodríguez-Reyna TS, Furuzawa-Carballeda J, Cabiedes J, Fajardo-Hermosillo LD, Martínez-Reyes C, Díaz-Zamudio M and Llorente L: Th17 peripheral cells are increased in diffuse cutaneous systemic sclerosis compared with limited illness: A cross-sectional study. Rheumatol Int 32: 2653-2660, 2012.

12. Kataoka H, Yasuda S, Fukaya S, Oku K, Horita T, Atsumi T and Koike T: Decreased expression of Runx1 and lowered proportion of Foxp $3^{+} \mathrm{CD} 25^{+} \mathrm{CD} 4^{+}$regulatory $\mathrm{T}$ cells in systemic sclerosis. Mod Rheumatol 25: 90-95, 2015.

13. Mo C, Zeng Z, Deng Q, Ding Y and Xiao R: Imbalance between $\mathrm{T}$ helper 17 and regulatory $\mathrm{T}$ cell subsets plays a significant role in the pathogenesis of systemic sclerosis. Biomed Pharmacother 108: 177-183, 2018.

14. Fenoglio D, Battaglia F, Parodi A, Stringara S, Negrini S, Panico N, Rizzi M, Kalli F, Conteduca G, Ghio M, et al: Alteration of Th17 and Treg cell subpopulations co-exist in patients affected with systemic sclerosis. Clin Immunol 139: 249-257, 2011.

15. Yanaba K, Yoshizaki A, Asano Y, Kadono T and Sato S: Serum interleukin 9 levels are increased in patients with systemic sclerosis: Association with lower frequency and severity of pulmonary fibrosis. J Rheumatol 38: 2193-2197, 2011.

16. Rubio-Rivas M, Royo C, Simeón CP, Corbella X and Fonollosa V: Mortality and survival in systemic sclerosis: Systematic review and meta-analysis. Semin Arthritis Rheum 44: 208-219, 2014.

17. Iudici M, van der Goes MC, Valentini G and Bijlsma JW: Glucocorticoids in systemic sclerosis: Weighing the benefits and risks-a systematic review. Clin Exp Rheumatol 31 (Suppl 76): $157-165,2013$.

18. Laar JMV,Farge D, Sont JK, Naraghi K, Marjanovic Z,Larghero J, Schuerwegh AJ, Marijt EWA, Vonk MC, Schattenberg AV, et al: Autologous hematopoietic stem cell transplantation vs intravenous pulse cyclophosphamide in diffuse cutaneous systemic sclerosis: A randomized clinical trial. JAMA 311: 2490-2498, 2014.

19. Arutyunyan I, Elchaninov A, Makarov A. and Fatkhudinov T: Umbilical cord as prospective source mesenchymal stem cell-based therapy. Stem Cells Int 2016: 6901286, 2016.

20. Sabapathy V, Sundaram B, V M S, Mankuzhy P and Kumar S: Human Wharton's jelly mesenchymal stem cells plasticity augments scar-free skin wound healing with hair growth. PLoS One 9: e93726, 2014.

21. Figueroa FE, Carrión F, Villanueva $S$ and Khoury $M$ : Mesenchymal stem cell treatment for autoimmune diseases: A critical review. Biol Res 45: 269-277, 2012.

22. Del Papa N, Quirici N, Soligo D, Scavullo C, Cortiana M, Borsotti C, Maglione W, Comina DP, Vitali C, Fraticelli P, et al: Bone marrow endothelial progenitors are defective in systemic sclerosis. Arthritis Rheum 54: 2605-2615, 2006.

23. Trojanowska M: Cellular and molecular aspects of vascular dysfunction in systemic sclerosis. Nat Rev Rheumatol 6: 453-460, 2010.

24. Christopeit M, Schendel M, Föll J, Müller LP, Keysser G and Behre G: Marked improvement of severe progressive systemic sclerosis after transplantation of mesenchymal stem cells from an allogeneic haploidentical-related donor mediated by ligation of CD137L. Leukemia 22: 1062-1064, 2008.

25. Sun LY, Zhang HY, Gu F, Feng XB, Zhao H and Han ZC: Treatment of refractory systemic sclerosis with human umbilical cord-derived mesenchymal stem cell transplantation. Cell Res 18 (S1): 1, 2008.

26. Martens TP, See F, Schuster MD, Sondermeijer HP, Hefti MM, Zannettino A, Gronthos S, Seki T and Itescu S: Mesenchymal lineage precursor cells induce vascular network formation in ischemic myocardium. Nat Clin Pract Cardiovasc Med 3 (Suppl 1): S18-S22, 2006.

27. Maria AT, Toupet K, Bony C, Pirot N, Vozenin MC, Petit B, Roger P, Batteux F, Le Quellec A, Jorgensen C, et al: Antifibrotic, antioxidant, and immunomodulatory effects of mesenchymal stem cells in HOCl-induced systemic sclerosis. Arthritis Rheumatol 68: 1013-1025, 2016. 
28. Zhao F, Zhang YF, Liu YG, Zhou JJ, Li ZK, Wu CG and Qi HW: Therapeutic effects of bone marrow-derived mesenchymal stem cells engraftment on bleomycin-induced lung injury in rats. Transplant Proc 40: 1700-1705, 2008.

29. Maria AT, Toupet K, Maumus M, Fonteneau G, Le Quellec A, Jorgensen C, Guilpain P and Noël D: Human adipose mesenchymal stem cells as potent anti-fibrosis therapy for systemic sclerosis. J Autoimmun 70: 31-39, 2016.

30. Li Y, Wang Z, Zhao Y, Luo Y, Xu W, Marion TN and Liu Y: Successful mesenchymal stem cell treatment of leg ulcers complicated by Behcet disease: A case report and literature review. Medicine (Baltimore) 97: e0515, 2018.

31. Wu D, Yang G, Gou Y, Xiao H, Liu W, Liang H, Zhou J, Huang Z, Zhang Y, Tan Z, et al: Human umbilical cord mesenchymal stem cells alleviate intestinal barrier injury in rats with severe acute pancreatitis. Int J Clin Exp Med 11: 3439-3446, 2018.

32. Yamamoto T, Takagawa S, Katayama I, Yamazaki K, Hamazaki Y, Shinkai $\mathrm{H}$ and Nishioka K: Animal model of sclerotic skin. I: Local injections of bleomycin induce sclerotic skin mimicking scleroderma. J Invest Dermatol 112: 456-462, 1999.

33. Livak KJ and Schmittgen TD: Analysis of relative gene expression data using real-time quantitative PCR and the 2(-Delta Delta C(T)) Method. Methods 25: 402-408, 2001.

34. Phan SH: Biology of fibroblasts and myofibroblasts. Proc Am Thorac Soc 5: 334-337, 2008.

35. Shi F, Harman J, Fujiwara K and Sottile J: Collagen I matrix turnover is regulated by fibronectin polymerization. Am J Physiol Cell Physiol 298: C1265-C1275, 2010.

36. Kubow KE, Vukmirovic R, Zhe L, Klotzsch E, Smith ML, Gourdon D, Luna S and Vogel V: Mechanical forces regulate the interactions of fibronectin and collagen I in extracellular matrix. Nat Commun 6: 8026, 2015.

37. Ehrlich HP, Allison GM and Leggett M: The myofibroblast, cadherin, alpha smooth muscle actin and the collagen effect. Cell Biochem Funct 24: 63-70, 2006

38. Besliu AN, Bănică LM, Lonescu R, Predeteanu D, Stăvaru C, Marica CM, Chiţonu C, Pistol G, Stefănescu M and Matache C: Role of cellular immunity in systemic sclerosis pathogenesis: Update on CD4+T cells population studies. Roum Arch Microbiol Immunol 68: 5-13, 2009.

39. Tolar J, Le Blanc K, Keating A and Blazar BR: Concise review: Hitting the right spot with mesenchymal stromal cells. Stem Cells 28: 1446-1455, 2010.

40. Ghannam S, Bouffi C, Djouad F, Jorgensen C and Noël D Immunosuppression by mesenchymal stem cells: Mechanisms and clinical applications. Stem Cell Res Ther 1: 2, 2010.

41. Beyer C, Schett G, Distler O and Distler JH: Animal models of systemic sclerosis: Prospects and limitations. Arthritis Rheum 62: 2831-2844, 2010

42. Ishikawa $\mathrm{H}$, Takeda $\mathrm{K}$, Okamoto $\mathrm{A}$, Matsuo $\mathrm{S}$ and Isobe $\mathrm{K}$ : Induction of autoimmunity in a bleomycin-induced murine model of experimental systemic sclerosis: An important role for CD4+ T cells. J Invest Dermatol 129: 1688-1695, 2009.

43. Avouac J: Mouse model of experimental dermal fibrosis: The bleomycin-induced dermal fibrosis. Methods Mol Biol 1142: 91-98, 2014

44. Chen JY, Mou XZ, Du XC and Xiang C: Comparative analysis of biological characteristics of adult mesenchymal stem cells with different tissue origins. Asian Pac J Trop Med 8: 739-746, 2015.

45. Ankrum JA, Ong JF and Karp JM: Mesenchymal stem cells: Immune evasive, not immune privileged. Nat Biotechnol 32 252-260, 2014.

46. Lim R, Milton P, Murphy SV, Dickinson H, Chan ST and Jenkin G: Human mesenchymal stem cells reduce lung injury in immunocompromised mice but not in immunocompetent mice. Respiration 85: 332-341, 2013.

47. Ho JH, Tseng TC, Ma WH, Ong WK, Chen YF, Chen MH, Lin MW, Hong CY and Lee OK: Multiple intravenous transplantations of mesenchymal stem cells effectively restore long-term blood glucose homeostasis by hepatic engraftment and $\beta$-cell differentiation in streptozocin-induced diabetic mice. Cell Transplant 21: 997-1009, 2012

48. Liu J, Lu X, Lou Y, Cai Y, Cui W, Wang J, Nie P, Chen L, Li B and Luo P: Xenogeneic transplantation of human placenta-derived mesenchymal stem cells alleviates renal injury and reduces inflammation in a mouse model of Lupus Nephritis. BioMed Res Int 2019: 9370919, 2019.

49. Hynes K, Bright R, Proudman S, Haynes D, Gronthos S and Bartold M: Immunomodulatory properties of mesenchymal stem cell in experimental arthritis in rat and mouse models: A systematic review. Semin Arthritis Rheum 46: 1-19, 2016.
50. Srour N and Thébaud B: Mesenchymal stromal cells in animal bleomycin pulmonary fibrosis models: A systematic review. Stem Cells Transl Med 4: 1500-1510, 2015.

51. Lin YT, Chern Y, Shen CK, Wen HL, Chang YC, Li H, Cheng TH and Hsieh-Li HM: Human mesenchymal stem cells prolong survival and ameliorate motor deficit through trophic support in Huntington's disease mouse models. PLoS One 6: e22924, 2011.

52. Kendall RT and Feghali-Bostwick CA: Fibroblasts in fibrosis: Novel roles and mediators. Front Pharmacol 5: 123, 2014.

53. Mayes MD: Endothelin and endothelin receptor antagonists in systemic rheumatic disease. Arthritis Rheum 48: 1190-1199, 2003.

54. Kissin EY, Lemaire R, Korn JH and Lafyatis R: Transforming growth factor beta induces fibroblast fibrillin-1 matrix formation. Arthritis Rheum 46: 3000-3009, 2002.

55. Yamamoto T, Takagawa S, Katayama I and Nishioka K: Anti-sclerotic effect of transforming growth factor-beta antibody in a mouse model of bleomycin-induced scleroderma. Clin Immunol 92: 6-13, 1999.

56. Postlethwaite AE, Shigemitsu $\mathrm{H}$ and Kanangat $\mathrm{S}$ : Cellular origins of fibroblasts: Possible implications for organ fibrosis in systemic sclerosis. Curr Opin Rheumatol 16: 733-738, 2004

57. Tsuji-Yamada J, Nakazawa M, Minami M and Sasaki T: Increased frequency of interleukin 4 producing CD4+ and CD8+ cells in peripheral blood from patients with systemic sclerosis. J Rheumatol 28: 1252-1258, 2001.

58. Sakkas LI, Xu B, Artlett CM, Lu S, Jimenez SA and Platsoucas CD: Oligoclonal $\mathrm{T}$ cell expansion in the skin of patients with systemic sclerosis. J Immunol (Baltimore, Md: 1950) 168: 3649-3659, 2002.

59. Jimenez SA and Derk CT: Following the molecular pathways toward an understanding of the pathogenesis of systemic sclerosis. Ann Intern Med 140: 37-50, 2004.

60. Yuan W, Yufit T, Li L, Mori Y, Chen SJ and Varga J: Negative modulation of alpha1(I) procollagen gene expression in human skin fibroblasts: Transcriptional inhibition by interferon-gamma. J Cell Physiol 179: 97-108, 1999.

61. Okamoto Y, Hasegawa M, Matsushita T, Hamaguchi Y, Huu DL, Iwakura Y, Fujimoto $\mathrm{M}$ and Takehara $\mathrm{K}$ : Potential roles of interleukin-17A in the development of skin fibrosis in mice. Arthritis Rheum 64: 3726-3735, 2012.

62. Lakos G, Melichian D, Wu M and Varga J: Increased bleomycin-induced skin fibrosis in mice lacking the Th1-specific transcription factor T-bet. Pathobiology 73: 224-237, 2006.

63. Aliprantis AO, Wang J, Fathman JW, Lemaire R, Dorfman DM, Lafyatis R and Glimcher LH: Transcription factor T-bet regulates skin sclerosis through its function in innate immunity and via IL-13. Proc Natl Acad Sci USA 104: 2827-2830, 2007.

64. Tan FK, Zhou X, Mayes MD, Gourh P, Guo X, Marcum C, Jin L and Arnett FC Jr: Signatures of differentially regulated interferon gene expression and vasculotrophism in the peripheral blood cells of systemic sclerosis patients. Rheumatology (Oxford) 45: 694-702, 2006

65. Singh RP, Hasan S, Sharma S, Nagra S, Yamaguchi DT, Wong DT, Hahn BH and Hossain A: Th17 cells in inflammation and autoimmunity. Autoimmun Rev 13: 1174-1181, 2014.

66. Ivanov II, Zhou L and Littman DR: Transcriptional regulation of Th17 cell differentiation. Semin Immunol 19: 409-417, 2007.

67. Xing X, Yang J, Yang X, Wei Y, Zhu L, Gao D and Li M: IL-17A induces endothelial inflammation in systemic sclerosis via the ERK signaling pathway. PLoS One 8: e85032, 2013.

68. Murata M,Fujimoto M,Matsushita T,Hamaguchi Y,Hasegawa M, Takehara K, Komura K and Sato S: Clinical association of serum interleukin-17 levels in systemic sclerosis: Is systemic sclerosis a Th17 disease? J Dermatol Sci 50: 240-242, 2008.

69. Yang X, Yang J, Xing X, Wan L and Li M: Increased frequency of Th17 cells in systemic sclerosis is related to disease activity and collagen overproduction. Arthritis Res Ther 16: R4, 2014.

70. Nakashima T, Jinnin M, Yamane K, Honda N, Kajihara I, Makino T, Masuguchi S, Fukushima S, Okamoto Y, Hasegawa M, et al: Impaired IL-17 signaling pathway contributes to the increased collagen expression in scleroderma fibroblasts. J Immunol (Baltimore, Md: 1950) 188: 3573-3583, 2012.

71. Wang D, Huang S, Yuan X, Liang J, Xu R, Yao G, Feng X and Sun L: The regulation of the Treg/Th17 balance by mesenchymal stem cells in human systemic lupus erythematosus. Cell Mol Immunol 14: 423-431, 2017.

72. Luz-Crawford P, Noël D, Fernandez X, Khoury M, Figueroa F, Carrión F, Jorgensen C and Djouad F: Mesenchymal stem cells repress Th17 molecular program through the PD-1 pathway. PLoS One 7: e45272,2012. 
73. Hu Y, Lou B, Wu X, Wu R, Wang H, Gao L, Pi J and Xu Y: Comparative study on in vitro culture of mouse bone marrow mesenchymal stem cells. Stem Cells Int 2018: 6704583, 2018.

74. Haddad R and Saldanha-Araujo F: Mechanisms of T-cell immunosuppression by mesenchymal stromal cells: What do we know so far? BioMed Res Int 2014: 216806, 2014.

75. Shi Y, Hu G, Su J, Li W, Chen Q, Shou P, Xu C, Chen X, Huang Y, Zhu Z, et al: Mesenchymal stem cells: A new strategy for immunosuppression and tissue repair. Cell Res 20: 510-518, 2010.

76. Le Blanc K and Mougiakakos D: Multipotent mesenchymal stromal cells and the innate immune system. Nat Rev Immunol 12 383-396, 2012.
77. Prockop DJ and Oh JY: Mesenchymal stem/stromal cells (MSCs): Role as guardians of inflammation. Mol Ther 20: 14-20, 2012.

78. Usunier B, Benderitter M, Tamarat R and Chapel A: Management of fibrosis: The mesenchymal stromal cells breakthrough. Stem Cells Int 2014: 340257, 2014.

c) (i) $(-)$ This work is licensed under a Creative Commons c. Attribution-NonCommercial-NoDerivatives 4.0 International (CC BY-NC-ND 4.0) License. 